\title{
Когерентный транспорт в квантовых системах: управляемые резонансы, особые точки и квантовые транзисторы
}

\author{
Горбацевич А.А., Шубин Н.М.
}

Физический институт им. Лебедева РАН, 119991, ГСП-1, Москва, Ленинский проспект, 53. Национальный исследовательский университет «МИЭТ», 124498, Москва, г. Зеленоград, пл. Шокина, 1.

DOI 10.34077/Semicond2019-142

Построена единая теория резонансов, антирезонансов и локализованных состояний в континууме в многосвязных молекулярных проводниках и оптических волноводах и описано явление спонтанного нарушения симметрии в бездиссипативных резонансно-туннельных структурах $[1,2]$. Показано, что положения максимумов туннельной прозрачности по энергии в точности соответствуют собственным значениям некоторого вспомогательного неэрмитового гамильтониана, который может быть легко получен из эффективного гамильтониана Фешбаха открытой квантовой системы. В симметричных структурах вспомогательный гамильтониан имеет РТ-симметричный вид (здесь Р и Т - опреации пространственной инверсии и обращения времени, соответственно). Слияние единичных пиков прозрачности геометрически симметричного квантового проводника в неединичный соответствует особой точке (exceptional point) вспомогательного гамильтониана и сопровождается нарушением пространственной симметрии распределения электронной плотности. Разработанный формализм описывает также слияние антирезонансов Фано-Фешбаха с формированием окон непрозрачности, что важно для термоэлектрических применений.

Описаны и проанализированы различные варианты управления баллистическим транспортом в квантовой системе [3] и показано, что только за счет сдвига антирезонанса, свзанного с деструктивной квантовой интерференцией, нельзя добиться существенного снижения управляющего напряжения и, соотвественно, энергопотребления. Однако такая возможность открывается при использовании наряду с деструктивной квантовой интерференцией явления коллапса резонансов в особой точке открытой квантовой системы, образованной молекулой и питающими электродами.

На основе построенной теории предложена модель молекулярного транзистора [4], переключение которого осуществляется в результате взаимодействия двух физических механизмов: резонанса Фано-Фешбаха и спонтанного нарушения РТ-симметрии, связанного с коллапсом резонансов в особой точке молекулы, соединеннной с электродами. Такой транзистор может быть реализован, например, на основе дирадикалов - органических молекулах с вырожденными орбиталями. Показано, что на базе РТ-симметричного интерференционного молекулярного транзистора возможно создать логические вентили с теоретически сколь угодно малыми рабочими напряжениями даже при комнатной температуре. Помимо молекулярных вычислительных устройств разработанная теория может служить основой для проектирования широкополосных фильтров, квантовых тепловых экранов и волноводов с управляемым формированием связанных состояний в континууме.

[1] Gorbatsevich A.A. and Shubin N.M., Annals of Physics, V. 376, p. 353-371 (2017).

[2] Gorbatsevich A.A. and Shubin N.M., Physical Review B, V. 96 (20), 205441 (2017).

[3] Горбаиевич А.А. и Шубин Н.М., УФН, Т. 188, с. 1209 (2018).

[4] Gorbatsevich A.A., Krasnikov G. Ya. and Shubin N.M. Sci. Rep. V. 8, 15780 (2018). 